\title{
Ecology of pathogenic and non-pathogenic Vibrio parahaemolyticus on the French Atlantic coast. Effects of temperature, salinity, turbidity and chlorophyll a
}

\author{
Deter Julie ${ }^{1,2}$, Lozach Solen ${ }^{1}$, Véron Antoine ${ }^{1,3}$, Chollet Jaufrey $^{1}$, Derrien Annick ${ }^{4}$ and Hervio-Heath \\ Dominique $^{1, *}$
}

\author{
${ }^{1}$ IFREMER, centre de Brest, Département Environnement, Microbiologie et Phycotoxines (EMP), \\ Laboratoire de Microbiologie, ZI de la pointe du diable, B.P. 70, 29280 Plouzané, France. \\ ${ }^{2}$ Laboratoire Ecosystèmes Lagunaires (ECOLAG), UMR 5119 CNRS-IFREMER-UM2-IRD, Université \\ de Montpellier II, Place Eugène Bataillon, 34095 Montpellier, France. \\ ${ }^{3}$ IFREMER, centre de Nantes, EMP/Laboratoire National de Référence Microbiologie des \\ Coquillages, BP 21105, 44311 Nantes Cedex 3, France. \\ ${ }^{4}$ IFREMER, LERPC, centre de La Rochelle, place Gaby Coll, BP 7, 17137 L'Houmeau, France. \\ *: Corresponding author : Hervio-Heath Dominique, Tel. (+33) 2982243 49; Fax (+33) 2982245 94, email \\ address : Dominique.Hervio.Heath@ifremer.fr
}

\begin{abstract}
:
Vibrio parahaemolyticus is one of the principal bacterial causes for seafood-borne gastroenteritis in the world. In the present study, three sites located on the French Atlantic coast were monitored monthly for environmental parameters over 1 year. The presence of total and pathogenic $V$. parahaemolyticus in sediment, water and mussel samples was detected following enrichment by culture and real-time PCR (toxR gene, tdh, trh1 and trh2 virulence genes). Using generalized linear models, we showed that the presence of $V$. parahaemolyticus in water could be explained by a combination of mean temperature over the 7 days before the day of sampling $(P<0.001)$ and turbidity $(P=0.058)$. In mussels, an effect of chlorophyll a $(P=0.005)$ was detected when an effect of the mean salinity over the 7 days before sampling was significant for the sediment $(P<0.001)$. We did not detect any significant effect of phytoplanktonic blooms or of the number of culturable bacteria on $V$. parahaemolyticus presence. No sample was revealed positive for tdh. The presence of trh1 and trh2 was positively influenced by the mean temperature during the 2 days before the day of sampling $(P<$ 0.001 and $P=0.032$ ). The importance of these ecological parameters is discussed in relation to the biology of $V$. parahaemolyticus.
\end{abstract}


2 Vibrio parahaemolyticus is a Gram-negative halophilic bacterium occurring naturally in

3 aquatic environments worldwide. Its abundance in water is seasonally variable, reaching its

4 maximum in summer when temperature is at its highest. The seasonal cycle of $V$.

5 parahaemolyticus in the sediment, water and plankton of Chesapeake Bay (USA) was first

6 reported by Kaneko and Colwell (1973; 1978). The bacterium might survive in sediments

7 during the winter and be released into the water column in late spring or early summer when

8 the temperature rises to $15^{\circ} \mathrm{C}$. Due to their filter-feeding activity, molluscs concentrate

9 bacteria in their tissues. The consumption of raw or undercooked contaminated seafood (and, more rarely, the contact between a wound and contaminated water) may lead to the transmission of bacteria to humans. However, only bacteria producing virulence factors, i.e. thermostable direct haemolysin (TDH) and/or TDH-related haemolysin (TRH), are considered to be pathogenic and can cause acute gastroenteritis (or, more rarely, invasive septicaemia) (Nishibuchi et al., 1995). Since 1996, the incidence of V. parahaemolyticus infections has increased dramatically from sporadic cases to large-scale outbreaks in America and epidemics in India and Asia (Matsumoto et al., 2000). This increase in incidence seems to be related to the emergence of a new pandemic clone, belonging to the O3:K6 serovar. In Europe, the risk of V. parahaemolyticus infections is considered to be very low (European Commission, 2001; Su and Liu, 2007). Consequently, the monitoring of this microorganism has not been included in the most important European infectious disease surveillance networks. However, validation of the ISO standard (ISO/TS 21872-1 and -2, 2007) and the preparation of a draft code of hygienic practice for Vibrio spp in seafood (Codex Committee on Food Hygiene, Codex Alimentarius Commission 2008) could contribute to the monitoring of this bacterium in shellfish and water for risk assessment purposes (WHO-FAO, 2005). In France, the temperature of coastal water tends to increase (this is monitored by IFREMER; see 
1 http://wwz.ifremer.fr/envlit/) and the O3:K6 serovar was shown to be present and persistent

2 (Quilici et al., 2005). However, apart from two outbreaks caused by imported shrimps (44

3 patients, Lemoine et al., 1999) and mussels (100 patients, Hervio-Heath et al., 2005), only

4 sporadic cases have been reported (Quilici et al., 2005) and there has only been one case of

5 mortal septicaemia (Quilici et al., 2004). A few environmental studies have shown the

6 presence of pathogenic strains in French coastal areas; $t d h+$ samples were never detected but

7 the prevalence of $t r h+$ strains ranged between 3 and $10 \%$ (Hervio-Heath et al., 2002; Robert-

8 Pillot et al., 2004). With a national production of $60000 \mathrm{t}$ per year, France is the third largest

9 mussel-producing country in Europe after Spain (250 000 t) and The Netherlands (100 000 t)

10 (Ifremer, 2006). Pertuis Breton (Poitou-Charentes Region) is an important area for this

11 activity economically, as it represents the second largest site for mussel culture in France

12 (production ranging from 7000 to 9000 t). Moreover, it provides most of the young mussels

to be grown on in Brittany and Normandy, two other French regions that do not produce spat (Dardignac-Corbeil, 2004). Poitou-Charentes is one of the two French regions where the highest number of vibrioses is reported (Quilici et al., 2004).

Numerous authors worldwide have become interested in the identification of the causative or associative factors that affect $V$. parahaemolyticus incidence, but no such study had been made in France. The distribution of total coastal V. parahaemolyticus populations is influenced by environmental factors including temperature in temperate zones (Duan and Su, 2005; Parveen et al., 2008), turbidity (Blackwell and Oliver, 2008; Parveen et al., 2008), salinity (Martinez-Urtaza et al., 2008) and factors related to plankton (planktonic species, 22 plankton detritus, or other particulate matter trapped during plankton hauls) due to attachment and/or a chitinoclastic activity (Kaneko et al., 1973). Similarly, climate, especially increasing temperature, has been shown to impact other pathogenic Vibrionaceae as $V$. vulnificus and $V$. cholerae diseases (Colwell, 1996; Lipp et al., 2002; Paza et al., 2007; de Magny et al., 2008). 
1 In particular, Vibrio cholerae has been extensively studied and associations with chlorophyll

2 a, rainfall and temperature have been shown (de Magny et al., 2008). In oysters, temperature,

3 turbidity and dissolved oxygen were also positively correlated with V. parahaemolyticus

4 densities (Parveen et al., 2008). All of these studies evaluated the links between

5 environmental factors and total V. parahaemolyticus but, as recently reported by Drake et al.

6 (2007), less is known about pathogenic strains in shellfish or water.

7 The objectives of the present study are first to determine the incidence of total and pathogenic

8 V. parahaemolyticus in mussels, water and sediment in the Pertuis Breton, and second, to

9 investigate the relationships with either abiotic (water temperature, salinity, turbidity, dissolved oxygen, chlorophyll $a$ ) or biotic parameters (phytoplankton blooms, number of 11 culturable bacteria).

\section{RESULTS AND DISCUSSION}

Description of the data

All environmental (water temperature, salinity, turbidity and cholorophyll a) parameters showed temporal variation during this one-year study (see Fig. 1). All of these parameters are presented in Figure 1. Technical problems with sensors (battery or biofouling) led to a few gaps in water temperature and salinity data. Measurements of dissolved oxygen were insufficient in number (only 18 observations) for the variable to be included in the statistical analyses. The monitoring of phytoplankton showed blooms of Pseudo-nitzschia sp,

Chaetoceros sp, Skeletonema costatum and Leptocylindrus (danicus and curvatulus), especially in May-June. All of these data were normalized (square root or log transformation) before statistical analysis.

Overall, total V. parahaemolyticus was present in mussels from May to October (present during winter at l'Eperon and in December-February and March in La Carrelère), in water 
1 from June to October and in sediment from June to December (see Fig. 2 for details). No

2 effect of sampling site was detected $(P=0.381)$ but the source effect was significant $(P=$

3 0.035). Data from the different sites were thus pooled but considered separately for mussels,

4 water and sediment in the statistical analyses concerning the presence of total $V$.

5 parahaemolyticus. When we considered the presence of pathogenic V. parahaemolyticus, tdh

6 was not detected in any of the 483 toxR positive (tox $R+$ ) samples, which is in agreement with

7 the other field studies conducted in France (Hervio-Heath et al., 2002; Robert-Pillot et al.,

8 2004). trh1 was detected in toxR + samples of mussels and sediment but never of water. The

9 presence of the trh2 gene was almost detected in all sites depending of the time. All of theses

results are presented in Fig. 3. Based on the lack of substantial differences for the presence of trh1 + or trh2+ samples (presence of pathogenic V. prahaemolyticus) between the sources of samples and/or sampling sites (all $P>0.400$ ), virulence data were pooled for the general linear models. Among the toxR+ samples, $24.64 \%$ (119/483) were trh+: 11/483 trh1+ with 0/223 isolated strains and 113/483 trh2+ with 34/223 isolated strains (15.25\%), a few samples were simultaneously trh1+ and trh2+. This prevalence is similar (considering isolated strains only) or a little greater (considering RT-PCR on DNA directly extracted from enriched samples and from strains) than those reported in previous short studies on the situation in France (3-15 \%, see Introduction).

The influence of abiotic parameters on the presence of total V. parahaemolyticus depends on the source (compartment)

$\underline{\text { In water, }}$ the best model (minimal AIC $=31.851, P<0.001, R^{2}=0.506$ ) explaining the presence of total V. parahaemolyticus was composed of mean temperature over the seven days before the date of sampling, hereon referred to as Temp-7 $(P<0.001)$, and turbidity $(P=$ 0.058) (see Table 1$)$. More than half of the variance $\left(R^{2}=0.506\right)$ in presence-absence of total 
$1 \quad V$. parahaemolyticus in water could be attributed to differences in water turbidity and Temp-7.

2 Increasing temperatures are linked to a higher risk of encountering V. parahaemolyticus in

3 water (mean temperature when total $V$. parahaemolyticus were detected was $20^{\circ} \mathrm{C}$, compared

4 with $13^{\circ} \mathrm{C}$ when they were not; Fig. 4). The same effect of temperature has been frequently

5 observed in previous studies (Cook et al., 2002; Blackwell and Oliver, 2008; Parveen et al.,

6 2008) and directly linked to the growing capacities of this bacterium. In the USA, the Gulf

7 Coast has the warmest mean water temperature $\left(22^{\circ} \mathrm{C}\right.$, although it can reach $\left.30^{\circ} \mathrm{C}\right)$ and was

8 seen to have the highest mean V. parahaemolyticus levels (11000 CFU/100 g oysters, 44/100

$9 \mathrm{ml}$ water), while the Pacific Coast presents the coldest water temperature and has lowest levels of $V$. parahaemolyticus (2100 CFU/100 g oysters, 2 CFU/100 ml water). The direct relationship between $V$. parahaemolyticus and water temperature seems to determine its 12 geographical distribution in the USA, Europe and Asia (Igbinosa et al., 2008). In the present study, we tested the effect of mean temperature calculated over a longer or shorter period (one, two and seven days before the sampling) and we found that a seven day-period allowed a better prediction of the presence of the bacteria. This makes sense, considering the time needed for the growth of $V$. parahaemolyticus once favourable temperature conditions arise.

17 Turbidity, although clearly less important, was also often linked to the bacteria presence because nutrients levels were higher (when waters are more turbid and richer in organic matter) stimulating bacterial growth or attachment to sediment particles, or reducing the penetration of solar radiation (Jones and Summer-Brason, 1998; Blackwell and Oliver, 2008;

21 Parveen et al., 2008).

22 In sediment, the best model (AIC $\left.=21.86, P<0.001, R^{2}=0.420\right)$ explaining the presence of V. parahemolyticus included only mean salinity over the seven days before sampling, Sal-7, $(P<0.001$; Table 1). The second best model included Temp-2 $(P=0.034)$ and Sal-2 $(P=$ 0.106, AIC of the model $=23.536, P=0.001, R^{2}=0.430$ ). A few studies have reported the 
1 influence of environmental parameters on the occurrence of vibrios in sediment. Kaneko and

2 Colwell $(1973 ;$ 1978) mention an effect of temperature on the Vibrio sp life cycle over-winter

3 in sediment. Blackwell and Oliver (2008) only detected a positive influence of pH (no

4 influence of water salinity or temperature) on the occurrence of $V$. vulnificus in sediment but

5 an effect of water temperature and turbidity (no impact of salinity) on V. parahaemolyticus. In

6 the present study, we showed that the bacteria are found during a longer period in sediment

7 than in water, but they are not detected year-round in sediment. Moreover, salinity of water

8 estimated over several days seemed to have a greater influence than temperature on the

9 presence of $V$. parahaemolyticus in sediment. A positive influence of water salinity on the occurrence of vibrios in water has often been detected when the range of variation of salinity levels is broad enough and the sample size sufficient (Cook et al., 2002; DePaola et al., 2003;

12 Zimmerman et al., 2007; Martinez-Urtaza et al., 2008; Parveen et al., 2008). The particular link that we found between salinity and presence of total V. parahaemolyticus in sediment may also be due to a direct influence of salinity and/or of freshwater inputs and other water perturbations. The higher the salinity of the sea water, the less important freshwater inputs become and the less the sea water would be perturbed by them. High salinity would, therefore, allow a more important sedimentation of bacteria. Salinity has been shown to influence the deposition of coliform bacteria in bottom muds of an estuarine system, thus prolonging their survival (Roper and Marshall, 1979).

In mussels, only chlorophyll $a$ was found to have a positive effect on the presence of the bacteria $\left(P=0.005\right.$, AIC of the model $\left.=28.160, P=0.013, R^{2}=0.149\right)$. However, biotic parameters (culturable bacteria or phytoplanktonic blooms) were never found to have a significant effect explaining the presence of total V. parahaemolyticus, even in mussels. This could be due to links between chlorophyll $a$ - phytoplankton - zooplankton, but unfortunately, we were not able to monitor zooplankton during this study to confirm this. 
1 Vibrio species have previously been shown to be influenced by the presence and abundance of

2 zooplankton due to attachment and/or the chitinoclastic activity of the bacteria (see the

3 introduction). The influence of chlorophyll $a$ detected in mussel samples is not due to the

4 bloom of any of the phytoplanktonic species reported in this study, but rather to an overall

5 effect or to the influence of zooplankton in relation to phytoplankton, linked in turn to

6 chlorophyll $a$. Chlorophyll $a$ in water, assessed with remote sensing, is already used to predict

7 cholera epidemics (de Magny et al., 2008). It also seems to be able to explain some of the

8 variation in V. parahaemolyticus levels in oysters (Phillips et al., 2007).

9

Influence of mean temperature recorded prior to sampling on the presence of pathogenic $\mathrm{V}$.

11 parahaemolyticus (detected in all toxR+ samples)

12 The presence of pathogenic $V$. parahaemolyticus is mainly positively linked to past

13 temperature Temp-2 $\left(P<0.001\right.$, AIC for the model $=22.920, P=0.031, R^{2}=0.047$ for tox $R^{+}$

14 trh1 + samples and $P=0.032$, AIC for the model $=38.635, P=0.011, R^{2}=0.017$ for tox $R+$

15 trh2+ samples; Table 1 and Fig. 3). The models are highly significant but only explain a small

16 part of the variance $(<5 \%)$, suggesting that the major influencing factor was not found.

17 Contrary to the model selected for the presence of total $V$. parahaemolyticus in water, Temp-2

18 was a better explaining factor than Temp-7 for pathogenic bacteria. This may be due to a

19 faster growth of pathogenic strains than non-pathogenic ones or simply because the lowest

20 variations in temperature occurred during summer (when pathogenic strains are more

21 frequent) making it unnecessary to calculate the mean over as long a period as seven days.

22 Moreover, even though several parameters influenced the presence of total $V$.

23 parahaemolyticus, only one (Temp-2) had an impact on the presence of pathogenic strains.

24 This raises two important points: although total $V$. parahaemolyticus data may be very

25 informative and easier to predict (greater $R^{2}$ ), it is worth studying bacteria that are more 
1 pathogenic as (1) according to Zimmerman et al. (2007) there are differences in predicting

2 total and pathogenic V. parahaemolyticus and (2) there is a strong disadvantage of being a

3 pathogenic strain during cold periods because pathogenic strains should have optimal growth

4 at warm temperatures (at least $37^{\circ} \mathrm{C}$ for a human body) to be pathogenic for humans.

5 Considering the three sites, $V$. parahaemolyticus was always detected in at least one of the

6 samples even during cold months. This suggests that $V$. parahaemolyticus is always present in

7 the environment and simply spatially redistributed between the different sources (shellfish,

8 sediment and water). No difference was detected between sources either for the presence (see

9 above) or the proportions of pathogenic strains (contingency table, all $P>0.05$ ). This

confirms the equal role of these different sources in the maintenance of pathogenic $V$.

11 parahaemolyticus, as recently proposed by Johnson et al. (2009) on genetic grounds.

12 This study is based on qualitative data, but it would now be better to work with quantities of total and pathogenic bacteria measured directly in the samples (without any enrichment step) using quantitative PCR. Thus, methods for concentration (filtration) of materials and DNA extractions need to be further developed and validated. This would remove any potential culture bias, to enable us to detect more $V$. parahaemolyticus cells and to study how the bacteria are spatially and temporally structured using a genetic approach (multilocus sequence analysis; Johnson et al., 2009). Further observations would contribute to the development of predictive models to evaluate proliferation of pathogenic species and thus, help to characterize risk periods for the benefit of public health.

\section{EXPERIMENTAL PROCEDURES}

Sampling sites and collection of samples

Pertuis Breton is located on the French Atlantic coast close to La Rochelle (Fig. 5). It 
1 rivers is relatively low (flow around $100 \mathrm{~m}^{3} / \mathrm{s}$ in winter) (Dardignac-Corbeil, 2004). Climate in

2 the region is oceanic with mean annual temperature around $12{ }^{\circ} \mathrm{C}$ (from -6 to $36{ }^{\circ} \mathrm{C}$, data

3 from the Poitou-Charentes Regional environmental observatory http://www.observatoire-

4 environnement.org/tbe/Climat.html).

5 Water $(\mathrm{N}=16 \times 3$ sites $=48)$ and mussel Mytilus edulis $(\mathrm{N}=48)$ samples were collected

6 monthly (twice monthly between May and August, noted "Month-1" and "Month-2") from

7 April 2008 to March 2009 from the three selected sites (L’Eperon, La Carrelère and Filière

8 W, see Fig. 5) by the Laboratoire Environnement Ressources du Pertuis Charentais (LER/PC)

9 IFREMER. Sediment samples $(\mathrm{N}=12 \times 2$ sites $=24)$ were collected monthly during the same

10 period in La Carrelère and L'Eperon (at low tide) but not in Filière W where the depth was

11 too great and the mussels are never out of the water. Mussels were sampled from "bouchots"

12 (wooden stakes) at La Carrelère and L'Eperon and on lines at Filière W. Water samples were

13 collected just below the surface. All microbiological analyses were initiated within 20-24 h of

14 sample collection following transportation to IFREMER Brest (transport in coolers at $\sim 12$ $\left.15{ }^{\circ} \mathrm{C}\right)$.

17 Environmental parameters were measured regularly by IFREMER LER/PC (between zero and 18 two days before or after the sampling on average) for the REseau de surveillance du 19 PHYtoplancton (REPHY) database (Ifremer phytoplankton monitoring network).

20 Phytoplanktonic data concerned the monitoring of toxic species such as Pseudo-Nitzschia,

21 Alexandrium and Dinophysis, but also the blooms of all other species (> 100000 cells / l).

22 Abiotic parameters were measured simultaneously in the upper $0.5 \mathrm{~m}$ of the surface water:

23 chlorophyll $a(\mu \mathrm{g} / \mathrm{l}$ ), turbidity (in formazin nephtelometric units = FNU) and dissolved

24 oxygen (mg / l, measured from June to September only) were measured. Temperature (in ${ }^{\circ} \mathrm{C}$ ) 
1 and salinity (no unit) were measured every 15 minutes by STPS sensors (NKE, France)

2 placed in the proximity of the sampling points.

\section{$4 \quad$ Preparation of samples}

5 Mussels were washed, opened using a sterile scalpel and emptied of sea water. All of the

6 following steps were done in sterilized conditions, with sterile instruments. Around $200 \mathrm{~g}$ of

7 flesh were collected per site. Liquid (hemolymph) and solid (remaining flesh) phases were

8 analysed separately for another experiment. As no difference was found between the two

9 matrices, final results were pooled as "mussel” in the present study. The solid phase was then

10 blended (3 x 20 sec. at high speed in a sterile Warring ${ }^{\circledR}$ Blender) and diluted 1:2 with sterile

11 alkaline peptone water $1 \% \mathrm{NaCl}$ (APW, 20g Bacto $^{\mathrm{TM}}$ peptone Becton Dickinson and Co, $10 \mathrm{~g}$

$12 \mathrm{NaCl}$ per liter, $\mathrm{pH}$ 8.2). Eight hundred $\mathrm{ml}$ water from each site were filtered (nitrocellulose

$130.22 \mu \mathrm{m}$, Millipore). Filter contents were re-suspended in $25 \mathrm{ml}$ (40 $\mathrm{ml}$ for l'Eperon and La

14 Carrelère in summer) of sterile artificial sea water (water and Instant ${ }^{\circledR}$ Ocean Sea Salt). For

15 sediment samples, 20 g were 1:2 diluted with APW 1\% $\mathrm{NaCl}$.

Detection of $\mathrm{V}$. parahaemolyticus

Direct culture and enrichment. Three filtrations of $10 \mathrm{ml}, 50 \mathrm{ml}$ and $100 \mathrm{ml}$ water (5, 10 and $25 \mathrm{ml}$ in summer) were realized for each site. Filters (nitrocellulose 0,22 $\mu \mathrm{m} \varnothing 47 \mathrm{~mm}$,

20 Millipore) were deposited onto three different culture media: Difco ${ }^{\mathrm{TM}}$ Marine Agar 2216

21 (=MA) (Becton Dickinson and Co.), Difco ${ }^{\mathrm{TM}}$ Thiosulfate Citrate Bile Salts Sucrose agar

22 (=TCBS) (Becton Dickinson and Co.), and CHROMagar ${ }^{\mathrm{TM}}$ Vibrio (=CA) (CHROMagar Paris

23 France). One filter was deposited per plate (three plates / culture medium /site). For each site,

$240.1 \mathrm{ml}$ of hemolymph and $0.1 \mathrm{ml}$ of the following two 10 -fold serial dilutions with buffered

25 physiological water (BPW, $4.52 \mathrm{~g} \mathrm{Na}_{2} \mathrm{HPO}^{4}, 12 \mathrm{H}_{2} \mathrm{O}, 0.4 \mathrm{~g} \mathrm{KH}_{2} \mathrm{PO}_{4}, 7.2 \mathrm{~g} \mathrm{NaCl}$ per liter) were 
1 spread plated onto TCBS, MA and CA. We proceeded similarly for the 1:2 mussel and 1:2

2 sediment homogenates. All the plates were incubated $24 \mathrm{~h}$ at $37^{\circ} \mathrm{C}$.

3 Undiluted hemolymph, re-suspended filter contents, a 1:10 dilution (APW) of the 1:2 mussel

4 homogenate and of the 1:2 sediment homogenate, were studied using the Most Probable

5 Number method (MPN) with three series of six tubes. Each series corresponded to a 1:10,

$6 \quad$ 1:100 and 1:1000 dilution (with APW). Tubes were incubated $20 \mathrm{~h}$ at $41{ }^{\circ} \mathrm{C}$ (a negative

7 control per series is placed at $4^{\circ} \mathrm{C}$ ). The number of total halophilic bacteria culturable at $41^{\circ} \mathrm{C}$

8 (selection of Vibrionaceae) was estimated using Mac Grady tables (Santé Canada, 1993).

9 Bacteria were isolated from $10 \mu \mathrm{l}$ of one positive tube per series on TCBS, MA and CA (incubation of one plate / medium during $24 \mathrm{~h}$ at $37^{\circ} \mathrm{C}$ ). No enumeration was done for sediment, but $6 \mathrm{ml}$ of 1:2 diluted sediment were enriched in $24 \mathrm{ml}$ of APW. After $20 \mathrm{~h}$ at 41 ${ }^{\circ} \mathrm{C}, 100 \mu \mathrm{l}$ of $10^{-4}, 10^{-5}$ and $10^{-6}$ dilution with BPW were spread-plated onto TCBS, MA and CA and incubated $24 \mathrm{~h}$ at $37^{\circ} \mathrm{C}$.

Biochemical identification. One colony of each morphotype per source/culture medium/site

(up to three colonies) suspected to be V. parahaemolyticus (green on TCBS, purple on CA, white on MA) was isolated twice on Bacto ${ }^{\mathrm{TM}}$ Heart Infusion agar with $2 \% \mathrm{NaCl}(=\mathrm{HI})$ (Becton Dickinson and Company) and incubated at $37^{\circ} \mathrm{C}$. Oxidase disks and Api20E system (BioMerieux, France) were used for the biochemical identification of presumed $V$. parahaemolyticus strains.

DNA extraction and detection of total and pathogenic V. parahaemolyticus by real-time PCR. DNA from oxidase positive strains was extracted from a $10 \mu \mathrm{l}$ inoculation loop washed twice with BPW (centrifugation $10 \mathrm{~min}$ at 5900 g). The pellet was suspended in $100 \mu \mathrm{l}$ of DNase, RNase, protease-free water (5-Prime inc.), heated $15 \mathrm{~min}$ at $100^{\circ} \mathrm{C}$ for cell lysis and 
1 centrifuged $10 \mathrm{~min}$ at $5900 \mathrm{~g}$ at $4{ }^{\circ} \mathrm{C}$. The lysate supernatant fluid was transferred to a new 0.5

2 ml tube.

3 Ten ml of enriched sediment were filtered (nitrocellulose $8 \mu \mathrm{m}$, Millipore) and centrifuged 15

$4 \mathrm{~min}$ at $2500 \mathrm{~g}$. The pellet was suspended in $2 \mathrm{ml}$ of BPW and centrifuged $5 \mathrm{~min}$ at $5900 \mathrm{~g}$

5 before the heating at $100{ }^{\circ} \mathrm{C}$ and performing the following steps.

6 Two ml of each MPN positive tube were centrifuged (10 min $5900 \mathrm{~g})$. DNA was extracted as

7 described above for strains. All DNA extractions were kept at $-20{ }^{\circ} \mathrm{C}$ until real-time PCR

8 (RT-PCR). DNA were tested for the presence of total and pathogenic V. parahaemolyticus

$9 \quad$ using respectively tox $R$ gene and $t d h$, trh1 and trh2 virulence gene detection (patent in process) by RT-PCR on a MX3000P $\mathrm{P}^{\mathrm{TM}}$ (Stratagene). Each toxR + sample was considered to be

11 positive for the presence of $V$. parahaemolyticus and tested for the presence of the virulence 12 genes.

Statistical analyses

We investigated the relationships between the environmental parameters measured and the presence of total $\left(\right.$ tox $\left.R^{+}\right)$and pathogenic $(t d h+, t r h 1+$ or trh2+) V. parahaemolyticus samples for each site and sampling session (binomial dependant variable: presence / absence). The dataset (overall pooled data) was tested for the effect of sampling site (Filière W, L'Eperon and La Carrelère) and source (mussel, water and sediment) using a logistic regression. We used generalized linear models with a logit function to test for the influence of (1) abiotic parameters (quantitative data): mean temperature (on the day of sampling itself, or estimated over the two preceding days $=$ Temp -2 or seven preceding days $=$ Temp-7) $\times$ mean salinity (on the day of sampling, or estimated over two preceding days $=$ Sal-2 or seven preceding days $=$ Sal-7) $\times$ turbidity $\times$ chlorophyll $a \times$ dissolved oxygen; and (2) biotic parameters: blooms of phytoplanktonic species (qualitative data) and number of culturable bacteria estimated by the 
1 MPN method in mussels and water (quantitative data). The interactions between all of the

2 variables in each model were investigated. We used an exhaustive approach, testing all the

3 interactions between variables, and searched for the most parsimonious (the least number of

4 variables but most explanation of results) using the Akaike Information Criterion (AIC)

5 (Akaike, 1974; Burnham and Anderson, 1998). All analyses were based on Legendre and

6 Legendre (1998) and performed with Statistica 6.1 (StatSoft, Inc.).

7

8

9

\section{ACKNOWLEDGEMENTS}

We thank James Grizon for his help with sampling and the EMP/MIC team for opening the mussels. We appreciate the assistance of Jean-Michel Chabirand and Alain Fillon for providing the sensor data and map, respectively. We thank Monique Pommepuy, Jean Côme Piquet, Mireille Ryckaert and Jean Prou for their scientific advice. This project was supported by IFREMER and a post-doctoral grant from the French Ministry of Higher Education and Research (Ministère de l’Enseignement Supérieur et de la Recherche).

Akaike, H. (1974) A new look at the statistical model identification. IEEE Trans Automat Contr 19: 716-723.

Blackwell, K.D., and Oliver, J.D. (2008) The ecology of Vibrio vulnificus, Vibrio cholerae and Vibrio parahaemolyticus in North Carolina estuaries. J Microbiol 46: 1-8.

Burnham, K.P., and Anderson, D.R. (1998) Model Selection and Inference - A practical information-theoretic approach. New York, USA: Springer-Verlag.

Cook, D.W., Bowers, J.C., and Depaola, A. (2002) Density of total and pathogenic $(t d h+)$ Vibrio parahaemolyticus in Atlantic and Gulf Coast molluscan shellfish at harvest. J Food Prot 65: 1873-1880.

Colwell, R.R. (1996) Global climate and infectious disease: the cholera paradigm. Science 274: 2025-2031. 
1 Dardignac-Corbeil, M.-J. (2004) La mytiliculture dans le "Pertuis Breton". Synthèse des

2 travaux réalisés de 1980 à 1992. Annales de la Société des sciences naturelles de la Charente-

3 Maritime: 3-79.

4 de Magny, G.C., Murtugudde, R., Sapiano, M.R.P., Nizam, A., Brown, C.W., Busalacchi, 5 A.J. et al. (2008) Environmental signatures associated with cholera epidemics. Proc Natl $6 \quad$ Acad Sci U S A 105: 17676-17681.

7 DePaola, A., Nordstrom, J.L., Bowers, J.C., Wells, J.G., and Cook, D.W. (2003) Seasonal 8 abundance of total and pathogenic Vibrio parahaemolyticus in Alabama oysters. Appl $9 \quad$ Environ Microbiol 69: 1521-1526. Drake, S.L., DePaola, A., and Jaykus, L.-A. (2007) An overview of Vibrio vulnificus and 11 Vibrio parahaemolyticus. Comp Rev Food Sci Food Safety 6: 120-144.

12 Duan, J., and Su, Y. (2005) Occurrence of Vibrio parahaemolyticus in two Oregon oystergrowing bays. J Food Sci 70: M58-M63.

European Commission (2001) Opinion of the scientific committee on veterinary measures relating to public health on Vibrio vulnificus and Vibrio parahaemolyticus.

Hervio-Heath, D., Colwell, R.R., Derrien, A., Robert-Pillot, A., Fournier, J.-M., and

17 Pommepuy, M. (2002) Occurence of pathogenic vibrios in coastal areas of France. J Appl Microbiol 92: 1123-1135.

Hervio-Heath, D., Zidane, M., Le Saux, J.-C., Lozach, S., Vaillant, V., Le Guyader, S., and Pommepuy, M. (2005) Toxi-infections alimentaires collectives liées à la consommation de moules contaminées par Vibrio parahaemolyticus : enquête environnementale. Bulletin épidémiologique de l'AFSSA 17: 1-2. IFREMER (2006). Aquaculture - Filière mollusques [www document]. URL http://wwz.ifremer.fr/aquaculture/filieres/filiere_mollusques/decouverte_mollusques 
1 Igbinosa, E.O., and Okoh, A.I. (2008) Emerging Vibrio species: an unending threat to public

2 health in developing countries. Res Microbiol 159: 495-506.

3 ISO/TS 21872-1 and -2, International Organization for Standardization. (2007) Microbiology

4 of food and animal feeding stuffs. Horizontal method for the detection of potentially

5 enteropathogenic Vibrio spp. Microbiology of food and animal feeding stuffs Vibrio spp. Part

6 1: Detection of Vibrio parahaemolyticus and Vibrio cholerae. Part 2: detection of species

7 other than Vibrio parahaemolyticus and Vibrio cholerae.

8 Johnson, C.N., Flowers, A.R., Young, V.C., Gonzalez-Escalona, N., Depaola, A., Noriea III,

$9 \quad$ N.F., and Grimes, D.J. (2009) Genetic relatedness among $t d h+$ and $t r h+$ Vibrio parahaemolyticus cultured from Gulf of Mexico oysters (Crassostrea virginica) and surrounding water and sediment. Microb Ecol 57: 437-443.

Jones, S.H., and Summer-Brason, B. (1998) Incidence and detection of pathogenic Vibrio sp. in a northern New England Estuary, USA. Conference Information: 2nd International Conference on Molluscan Shellfish Safety 1997, Iloilo (Philippines). J Shellfish Res 17: 1665-1669.

Kaneko, T., and Colwell, R.R. (1973) Ecology of Vibrio parahaemolyticus in Chesapeake Bay. J Bacteriol 113: 24-32.

Kaneko, T., and Colwell, R.R. (1978) Annual cycle of Vibrio parahaemolyticus in Chesapeake Bay. Microbiol Ecol 4: 135-155.

Legendre, P., and Legendre, L. (1998) Numerical Ecology. Developments in environmental modelling. Amsterdam, Netherlands: Elsevier Sciences B. V.

Lemoine, T., Germanetto, P., and Giraud, P. (1999) Toxi-infection alimentaire collective à Vibrio parahaemolyticus. Bulletin Epidémiologique Hebdomadaire 10: 37-38.

Lipp, E.K., Huq, A., and Colwell, R.R. (2002) Effects of global climate on infectious disease: the Cholera model. Clin Microbiol Rev 15: 757-770. 
1 Martinez-Urtaza, J., Lozano-Leon, A., Varela-Pet, J., Trinanes, J., Pazos, Y., and Garcia-

2 Martin, O. (2008) Environmental determinants of the occurrence and distribution of Vibrio

3 parahaemolyticus in the rias of Galicia, Spain. Appl Environ Microbiol 74: 265-274.

4 Matsumoto, C., Okuda, J., Ishibashi, M., Iwanaga, M., Garg, P., Rammamurthy, T. et al.

5 (2000) Pandemic spread of an O3:K6 clone of Vibrio parahaemolyticus and emergence of

6 related strains evidenced by arbitrarily primed PCR and toxRS sequence analyses. J Clin

$7 \quad$ Microbiol 32: 578-585.

8 Nishibuchi, M., and Kaper, J.B. (1995) Thermostable direct hemolysin gene of Vibrio

9 parahaemolyticus: a virulence gene acquired by a marine bacterium. Infect Immun 63: 2093102099.

11 Parveen, S., Hettiarachchi, K.A., Bowers, J.C., Jones, J.L., Tamplin, M.L., McKay, R. et al.

12 (2008) Seasonal distribution of total and pathogenic Vibrio parahaemolyticus in Chesapeake

Bay oysters and waters. J Food Microbiol 128: 354-361.

Paza, S., Bisharatb, N., Pazc, E., Kidara, O., and Cohenb, D. (2007) Climate change and the mergence of Vibrio vulnificus disease in Israel. Env Res 103: 390-396.

Phillips, A.M.B., DePaola, A., Bowers, J., Ladner, S., and Grimes, D.J. (2007) An evaluation of the use of remotely sensed parameters for prediction of incidence and risk associated with Vibrio parahaemolyticus in Gulf Coast oysters (Crassostrea virginica). J Food Protec 70: 879-884.

Quilici, M.-L., Guenole, A., Lemee, L., and Fournier, J.-M. (2004) Les infections à vibrions non cholériques en France : cas identifiés de 2001 à 2003 par le Centre national de référence des vibrions et du choléra. Synthèse du Centre national de référence des vibrions et du choléra.

Quilici, M.-L., Robert-Pillot, A., Picart, J., and Fournier, J.-M. (2005) Pandemic Vibrio parahaemolyticus O3:K6 spread, France. Emerg Infect Dis 11: 1148-1149. 
1 Robert-Pillot, A., Guénolé, A., Lesne, J., Delesmont, R., Fournier, J.-M., and Quilici, M.-L.

2 (2004) Occurence of the $t d h$ and trh genes in Vibrio parahaemolyticus isolates from waters

3 and raw shellfish collected in two French coastal areas and from seafood imported into

4 France. Int J Food Microbiol 91: 319-325.

5 Roper, M.M., and Marshall, K.C. (1979) Effects of salinity on sedimentation and of

6 participates on survival of bacteria in estuarine habitats. Geomicrobiol J 1: 103-116.

7 Santé Canada (1993) Compendium des méthodes. Méthodes officielles pour l'analyse

8 microbiologique des aliments. In: Direction Générale des Produits de Santé et des Aliments -

9 Santé Canada, Annexe D vol 1-3.

Su, Y.-C., and Liu, C. (2007) Vibrio parahaemolyticus: A concern of seafood safety. Food

11 Microbiol 24: 549-558.

12

WHO, FAO (2005) Risk assessment of Vibrio vulnificus in raw oysters, MRA series 8.

Zimmerman, A.M., Depaola, A., Bowers, J.C., Krantz, J.A., Nordstrom, J.L., Johnson, C.N., and Grimes, D.J. (2007) Variability of total and pathogenic Vibrio parahaemolyticus densities in Northern Gulf of Mexico water and oysters. App Env Microbiol 73: 7589-7596.

\section{TABLE AND FIGURE LEGENDS}

Table 1. Description of the models selected to explain the presence / absence (P/A) of total and pathogenic (presence of trh1 or trh2 genes) Vibrio parahaemolyticus (=Vp). Sal-y or Temp-y = mean salinity or temperature estimated over $y$ days before the sampling.

\begin{tabular}{ccccc}
\hline $\begin{array}{c}\text { Variable to be } \\
\text { explained }\end{array}$ & $\begin{array}{c}\text { Variables included in the } \\
\text { selected model }\end{array}$ & Log likelihood & $\chi^{2}$ & $P$-value \\
\hline P/A Vp in water & Temp-7 & -41.155 & 40.309 & $<0.001$ \\
\hline
\end{tabular}




\begin{tabular}{ccccc} 
& Turbidity & -21.800 & 3.591 & 0.058 \\
\hline P/A Vp in sediment & Sal-7 & -18.094 & 15.187 & $<0.001$ \\
\hline P/A Vp in mussels & Chlorophyll a & -27.017 & 8.034 & 0.005 \\
\hline P/A trh1 gene in & Temp-2 & -23.102 & 13.205 & $<0.001$ \\
tox + samples & & & & \\
\hline P/A trh2 gene in & Temp-2 & -18.811 & 4.623 & 0.032 \\
tox + samples & & & & \\
\hline
\end{tabular}

1

2 
2 Figure 1. Variation of the abiotic parameters: mean temperature (white circles) and salinity

3 (black squares) of the day of sampling, turbidity (black triangles) and chlorophyll $a$ (crosses).

4 The study period (April 2008- March 2009) covered 16 sampling sessions (generally one

5 sample per month year round and two per month between May and August) at a) Filière W, b)

6 L'Eperon and c) La Carrelère. Gaps in temperature and salinity measurement are due to

7 technical problems with sensors. 
a)

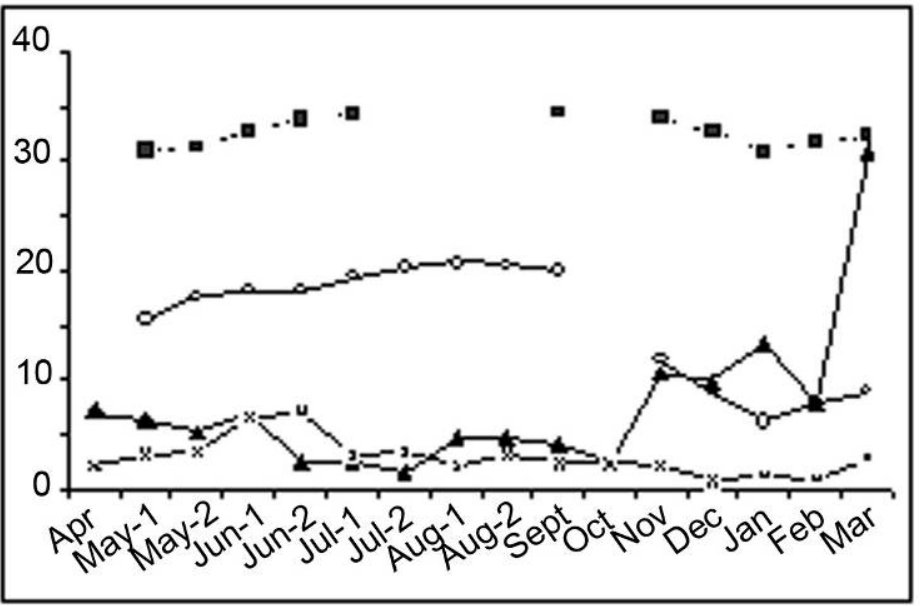

b)

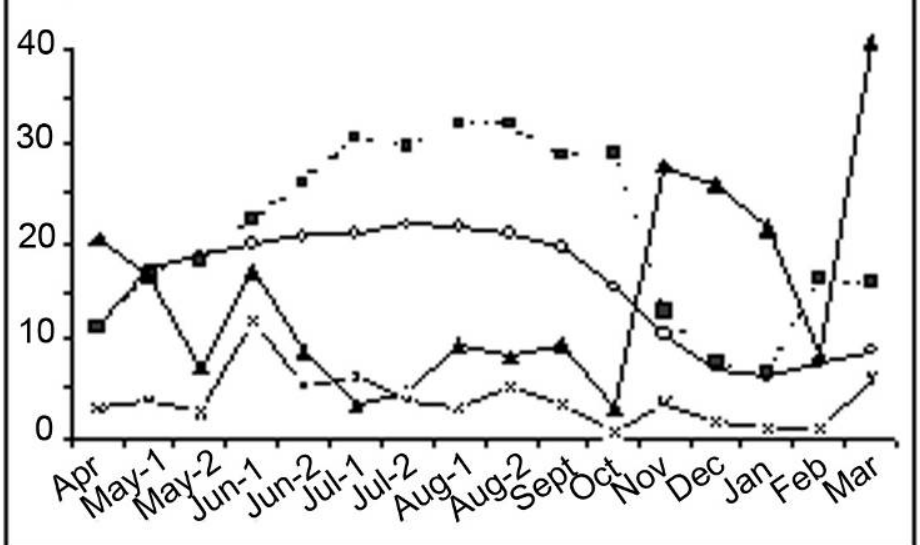

c)

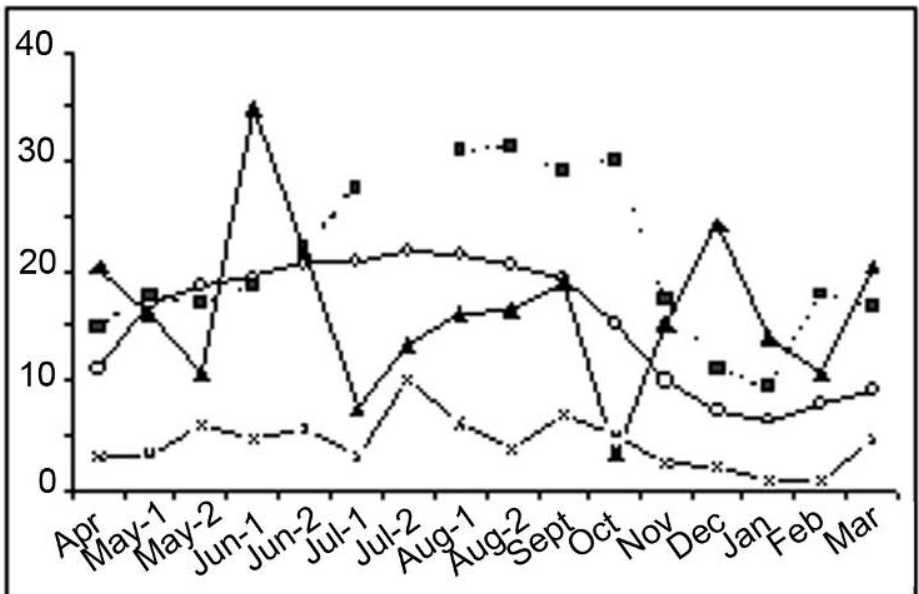


1 Figure 2. Presence (P) / Absence (A) of total Vibrio parahaemolyticus in mussels (full black

2 lines, squares), water (dotted grey lines, circles) and sediment (full grey lines, small triangles)

3 per date of sampling at a) Filière W, b) L’Eperon and c) La Carrelère.

a)
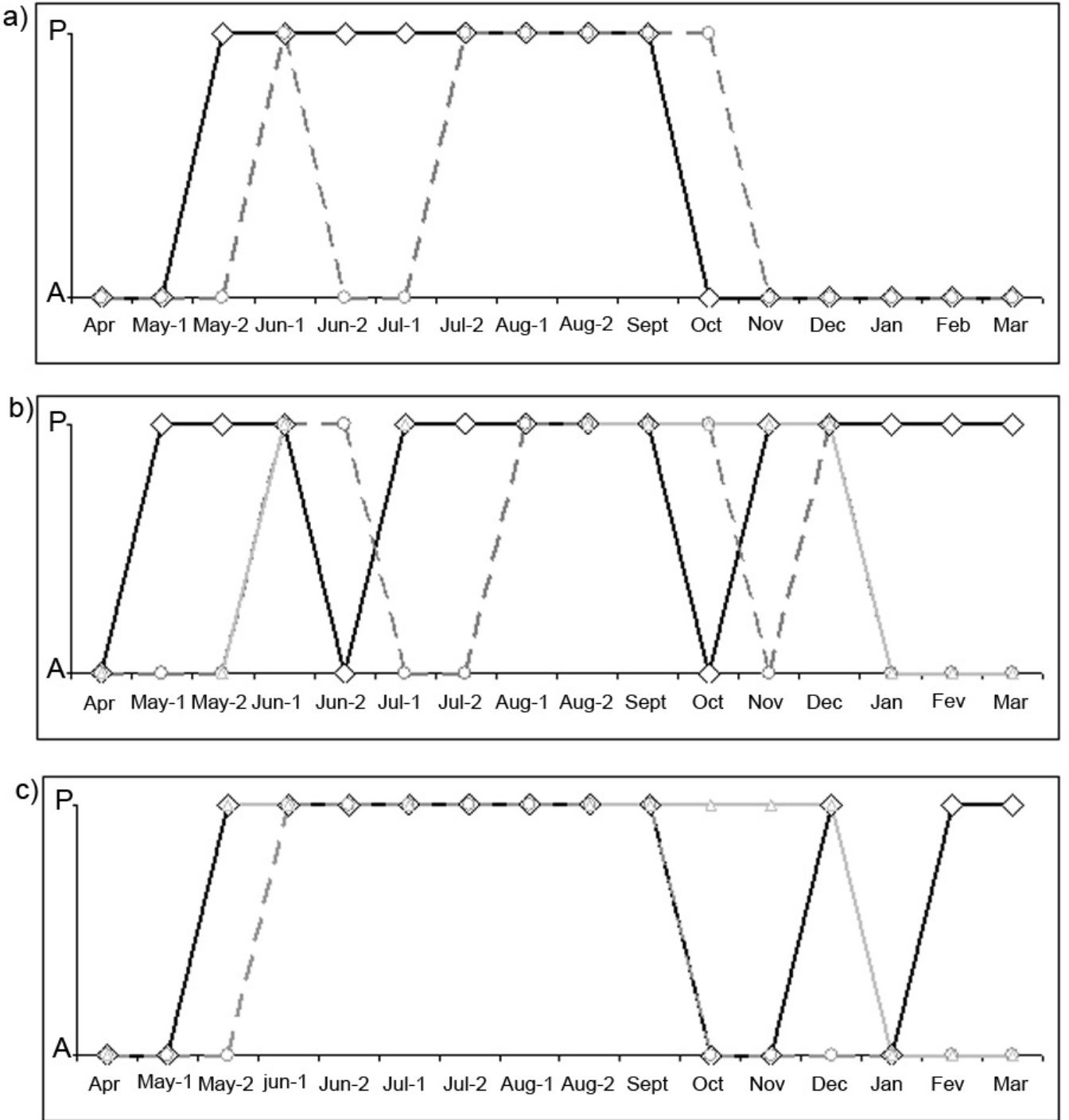

4

5 
1 Figure 3. Variation of mean water temperature $\left({ }^{\circ} \mathrm{C}\right)$ estimated over the two days before the

2 day of sampling (Temp-2) at a) Filière W, b) L'Eperon and c) La Carrelère. Presence of

3 pathogenic (trh1+ in black, trh2+ in grey, no tdh+) Vibrio parahaemolyticus in mussels

4 (squares), water (circles) and sediment (triangles) are indicated on the graphs. Gaps in

5 temperature measurements are due to technical problems with sensors.

6 
a)

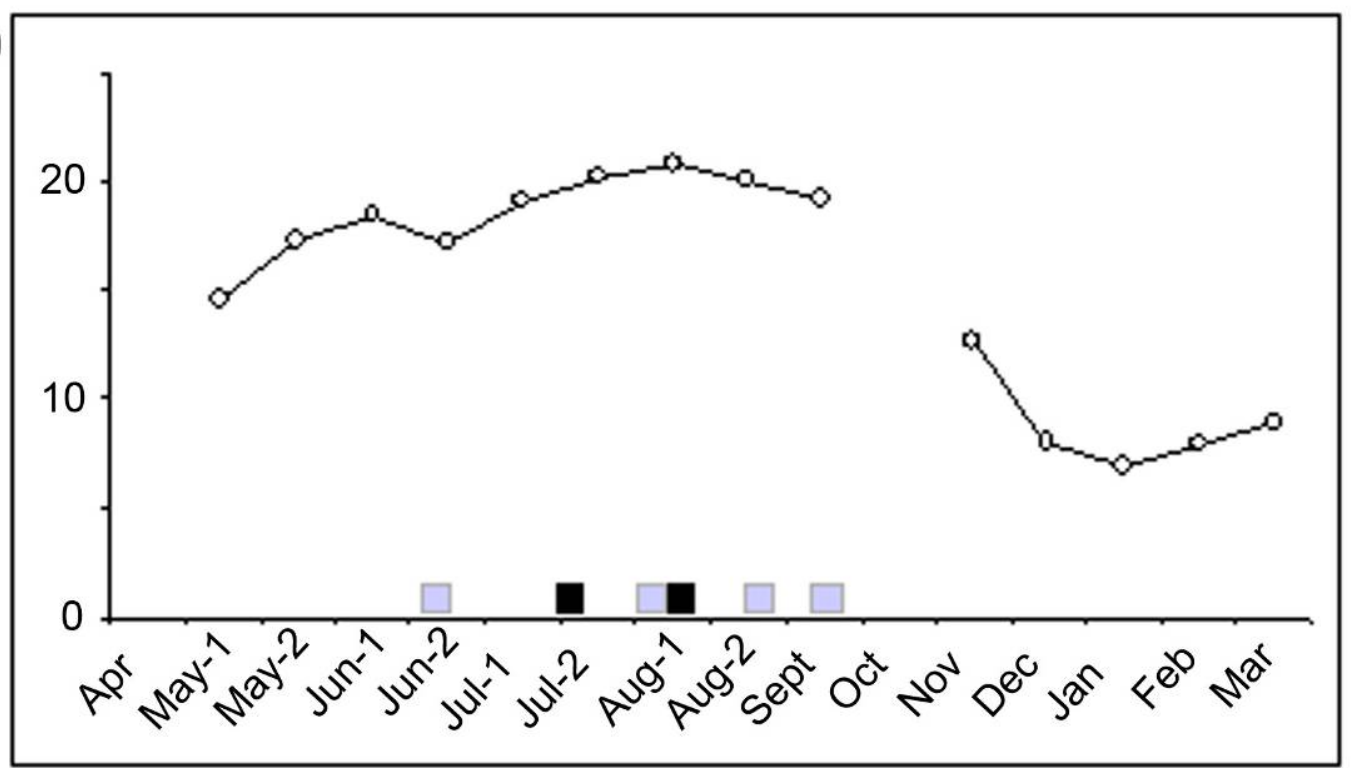

b)

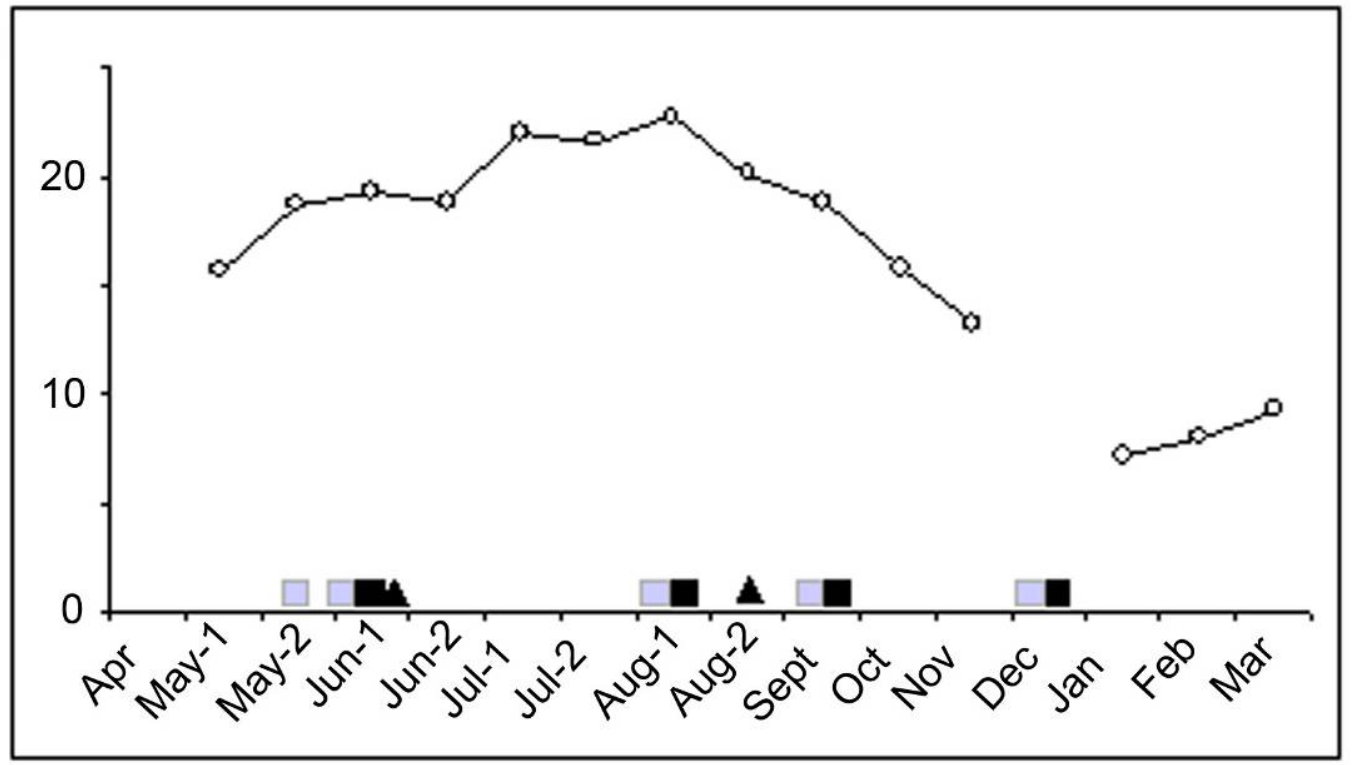

c)

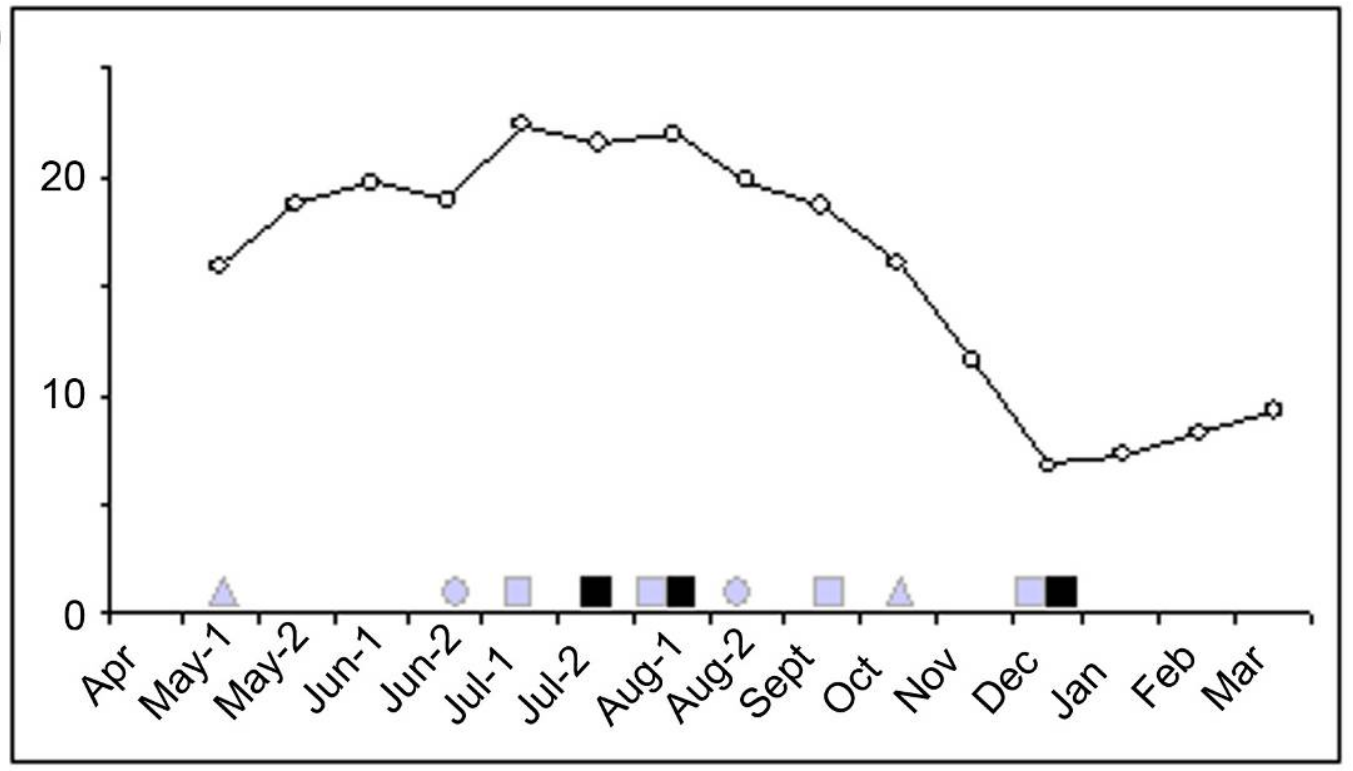


1 Figure 4. Positive relationship between the presence and absence of total Vibrio

2 parahaemolyticus in water and mean water temperature over the seven days before sampling

3 (Temp-7 in ${ }^{\circ} \mathrm{C}$ ). Squares represent the median of the data, box-plots show $25 \%$ to $75 \%$ of the

4 data (boxes) and horizontal traits, how minimal and maximal values are distributed. Circles

5 represent atypical points (the detection of total V. parahaemolyticus in October 2008 at

6 L’Eperon).

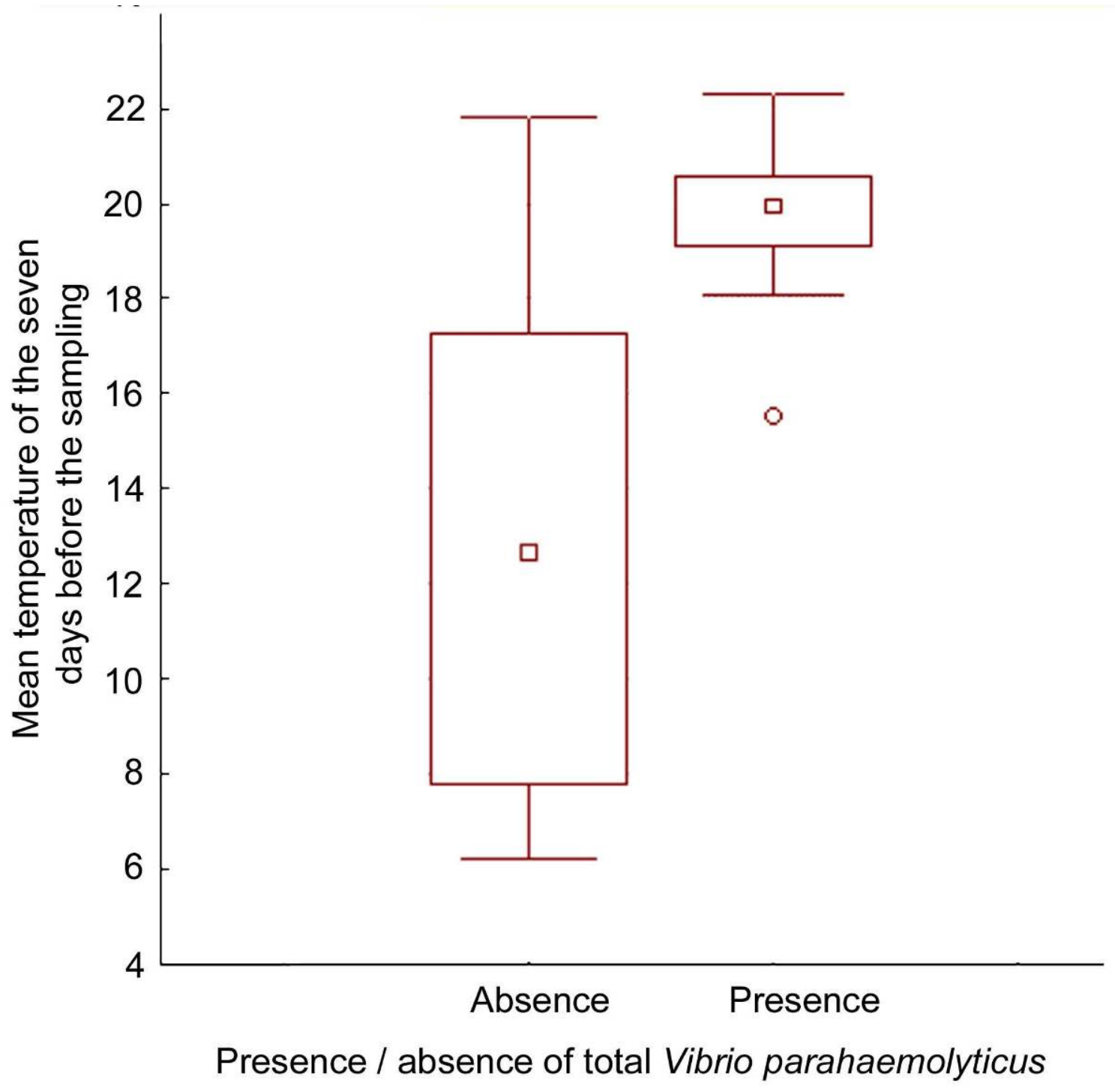

8 
1 Figure 5. Map of the Pertuis Breton showing the locations of the sampling sites and sensors.

2

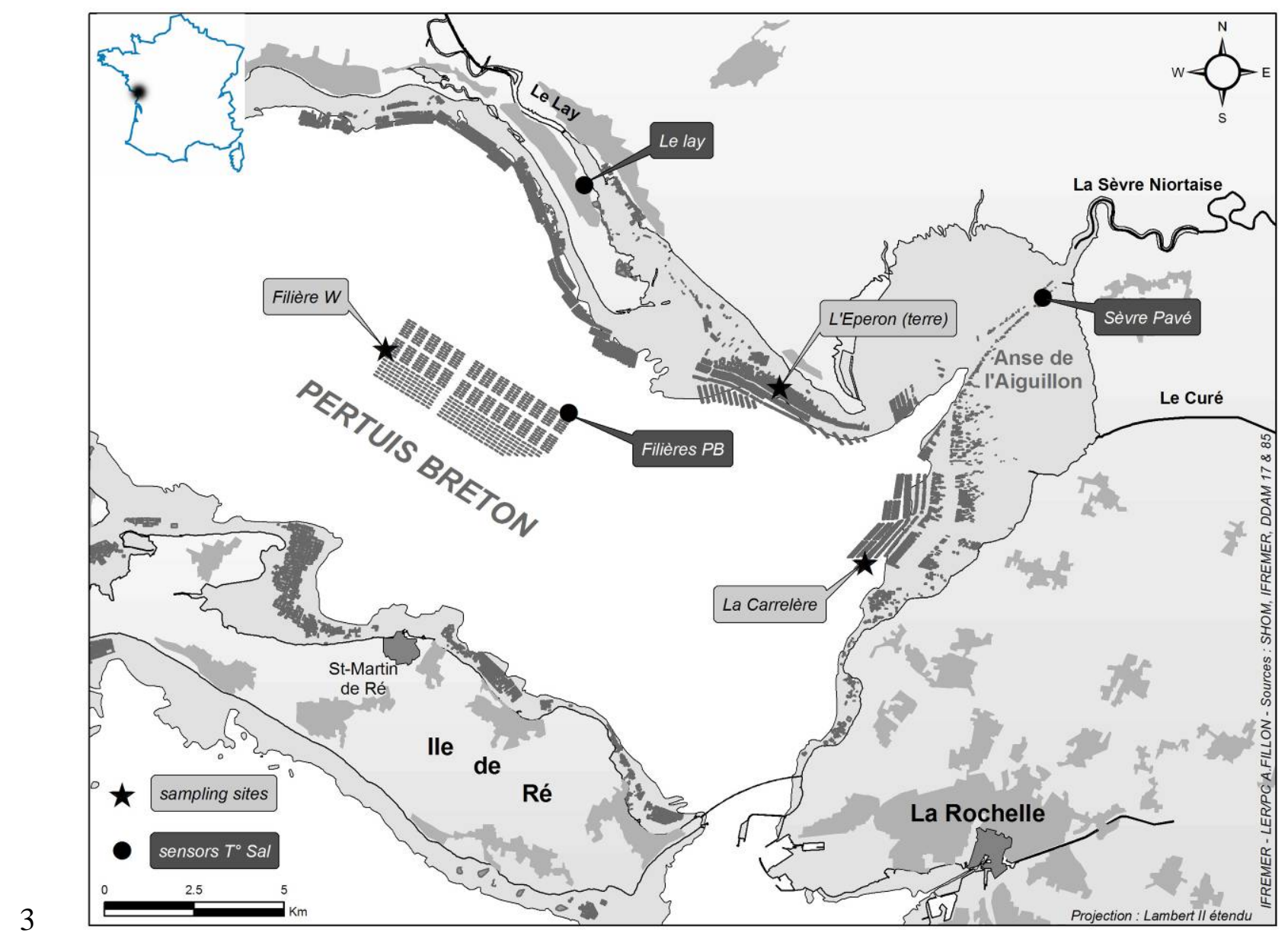

